\title{
Perinatal Nitric Oxide Synthase Inhibition Retards Neonatal Growth by Inducing Hypertrophic Pyloric Stenosis in Rats
}

\author{
CYNTHIA A. VOELKER, MARK J. S. MILLER, XIAO-JING ZHANG, SANDRA \\ ELOBY-CHILDRESS, DAVID A. CLARK, AND MARIA R. PIERCE
}

\author{
Department of Pediatrics, Tulane Medical Center, New Orleans, Louisiana 70112 [M.R.P] and \\ Department of Pediatrics, Louisiana State University Medical Center, New Orleans, Louisiana 70112 \\ [C.A.V., M.J.S.M., X.-J.Z., S.E.-C., D.A.C.]
}

\begin{abstract}
Administration of the nitric oxide synthase (NOS) inhibitor, $N^{\mathrm{G}}$-nitro-L-arginine methyl ester (L-NAME) during pregnancy has been shown to compromise fetal growth. This study was designed to determine whether aminoguanidine, a predominate inhibitor of inducible NOS, affects fetal outcome. In addition, we extended the prenatal administration of L-NAME into the postnatal period (14 d) to determine whether neonatal growth and maturation were also affected. L-NAME, but not aminoguanidine, compromises fetal and placental growth. When compared with control 14-d-old pups, postnatal L-NAME compromised neonatal growth, whether it was given directly (intraperitoneally) (39.7 \pm 1.1 versus $24.1 \pm 1.0 \mathrm{~g})$ or indirectly $(38.6 \pm 0.5$ versus $22.2 \pm$ $1.2 \mathrm{~g}$ ) via maternal breast milk. Neonatal growth retardation was asymmetric, with brain sparing, suggesting a nutritional origin. L-NAME administration resulted in growth retardation that extended into adulthood, without evidence of catch-up growth. Treated neonates displayed the hallmarks of hypertrophic pyloric stenosis. Significant increases in stomach weight/pup weight (9.9 \pm 0.3 versus $8.2 \pm 0.4 \times 10^{3}$ ) and stomach volume/pup weight $(12.0 \pm 0.6$ versus $9.4 \pm 0.6 \mathrm{~mL} / 100 \mathrm{~g})$ with a concomitant
\end{abstract}

\section{ABSTRACT}

decrease in small intestine weight/length $(2.10 \pm 0.08$ versus $3.18 \pm 0.13 \mathrm{~g} / 100 \mathrm{~cm}$ ) was noted in treated versus control pups $(p<0.05)$. Muscularis hypertrophy at the pyloric sphincter in the L-NAME-treated pups was noted by histology. Blood pressure was elevated in the L-NAME-treated pups $(93 \pm 6$ versus 60 $\pm 5 \mathrm{~mm} \mathrm{Hg}$ in control pups, $p<0.05)$. These findings are consistent with inhibition of neuronal and endothelial NOS activity. We conclude that NO, formed via the constitutive isoforms of NOS, is a critical determinant of fetal and neonatal growth and maturation. (Pediatr Res 38: 768-774, 1995)

Abbreviations
NO, nitric oxide
cNOS, nitric oxide synthase
iNOS, inducible nitric oxide synthase
L-NAME, $N^{G}$-nitro-L-arginine methyl ester
HPS, hypertrophic pyloric stenosis
VIP, vasoactive intestinal polypeptide

nidine, although not a L-arginine analog, predominately inhibits the inducible NOS isoform (9).

NO formation is up-regulated in pregnancy (10). The uteroplacental unit via both constitutive and inducible pathways appears to form NO under these conditions $(11,12)$. We recently reported that early third trimester (gestational d 1319) NOS inhibition with L-NAME in rats, although not affecting indices of maternal health, resulted in marked fetal and placental growth retardation (13). To better address the pathogenesis of the intrauterine growth retardation observed with third trimester NOS inhibition, the present studies were designed to determine whether the timing and duration of prenatal NOS inhibition affects the degree of growth retardation observed and whether prenatal NOS inhibition with the predominately inducible NOS inhibitor, aminoguanidine, would alter intrauterine growth. In addition, as there are no reports on
Received October 3, 1994; accepted June 14, 1995.

Correspondence: Maria R. Pierce, M.D., Department of Pediatrics, Section of Neonatology, Tulane Medical Center, 1430 Tulane Avenue, New Orleans, LA 70112.

Supported in part by National Institutes of Health Grant RO1 HD31885 (to M.J.S.M.) and American Heart Association, Louisiana Chapter (to M.R.P.). 
the role of NO on neonatal growth and maturation, we extended the prenatal administration of L-NAME into the postnatal period (i.e. perinatal).

\section{METHODS \\ Prenatal Studies}

Chronic second and late third trimester NOS inhibition with L-NAME. Timed pregnant rats (Holtzman, Harlan Sprague-Dawley) were obtained on gestational d 6 of a 22-d gestation. They were randomly assigned to one of three treatment groups: the first received the NOS inhibitor, L-NAME (Sigma Chemical Co., St. Louis, MO) at 0.3 or $1.0 \mathrm{mg} / \mathrm{mL}$ in the drinking water, for 14 prenatal days (gestational d 6-19). Based on water consumption these doses of L-NAME approximate to 55 and $180 \mathrm{mg} / \mathrm{kg} /$ day, respectively. The second group received L-NAME (same doses) for 4 prenatal days (gestational d 16-19). The third group was a water only control. Daily fluid consumption was followed per cage of two to three animals that were uniformly treated, to estimate daily dosage. The dose range used in this study encompassed doses known to reduce the elevated NO production associated with experimental inflammatory bowel disease $(5,14)$ and elicit hypertension in adult animals (14-16). This oral route of administration has been routinely used by ourselves $(5)$ and others $(15,16)$ and is a simple and reliable approach to the chronic administration of NOS inhibitors.

On gestational d 20, dams were killed by an overdose of intramuscular ketamine:xylazine anesthesia (Ketalar, ParkeDavis, Morris Plains, NJ, and Rompun, Paynet Cutter Labs, Shawnee, KS). Uterine horns were removed in block. Fetuses and placentas were removed from the uterus and weighed. Fetuses were euthenized with an overdose of ketamine and xylazine.

Aminoguanidine studies. Timed pregnant rats were obtained in the third trimester (gestational d 13) [timing based on the above results and our earlier study (13)]. They were randomly assigned to one of two treatment groups; the first received aminoguanidine (Sigma Chemical Co.), a prototypical iNOS inhibitor, at $1.0 \mathrm{mg} / \mathrm{mL}$ for 7 prenatal days (gestational d 13-19), which approximates to $180 \mathrm{mg} / \mathrm{kg} / \mathrm{d}$ in the drinking water. The dose of aminoguanidine used has been shown by us (17) and others to inhibit iNOS $(14,18,19)$. The second group was a water-only control. On gestational d 20, dams were killed, and fetuses and placentas were removed and weighed.

\section{Perinatal Studies}

Postnatal growth. Timed pregnant rats were obtained on gestational d 6 and randomly assigned to one of two main groups, A and B (Fig. 1). Group A consisted of dams receiving L-NAME $(1.0 \mathrm{mg} / \mathrm{mL})$ for either 7 or 14 prenatal days, in the drinking water. Group B consisted of dams not receiving prenatal treatment. After a normal parturition, newborns in group A were subdivided into those receiving 14 postnatal days of either L-NAME $(1.0 \mathrm{mg} / \mathrm{mL}$ of maternal drinking water, i.e. through maternal breast milk) or water only. Newborns in group B were subdivided into those receiving 14 postnatal days

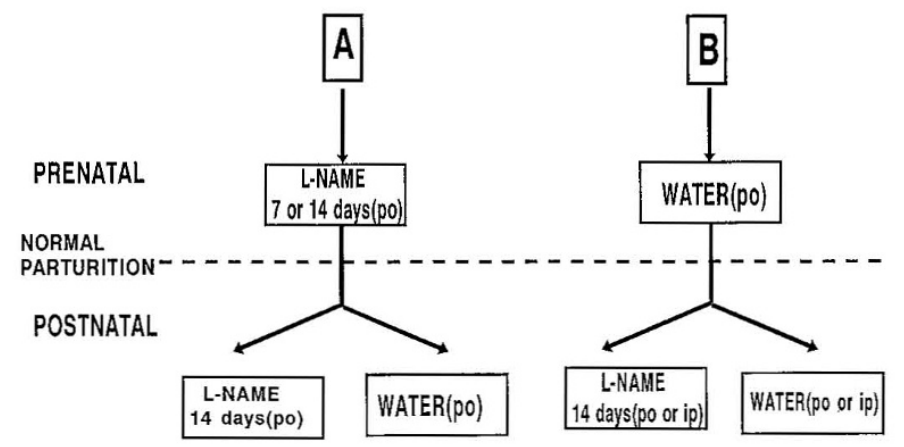

Figure 1. Perinatal growth treatment scheme. Group A received L-NAME $(1.0 \mathrm{mg} / \mathrm{mL})$ for either 7 or 14 prenatal days, in the drinking water immediately before a normal parturition. Postnatal L-NAME was administered either indirectly in maternal breast milk ( $p o$ ) or directly by intraperitoneal $(i p)$ injections.

of either L-NAME or water. For group B L-NAME was administered either indirectly via maternal breast milk $(1.0 \mathrm{mg} / \mathrm{mL}$ of maternal drinking water), or directly by intraperitoneal injections (as described below). Intraperitoneal L-NAME was given to ensure that findings were not secondary to maternal factors. L-NAME $(180 \mathrm{mg} / \mathrm{kg})$ in $0.1 \mathrm{~mL}$ of water was injected daily for 14 postnatal days; controls received an equal volume of water. After this 2-wk treatment period, control and L-NAME groups were handled in a similar manner; nursing was continued until weaning. Growth was monitored for 6 postnatal months. Once noting a remarkable delay in postnatal growth at $14 \mathrm{~d}$ of life with L-NAME, we explored a variety of parameters in an attempt to understand the pathogenesis involved.

Postnatal growth retardation. All of the pups receiving L-NAME treatments (pre- or postnatal only, or pre- and postnatal) were significantly smaller then their control counterparts at $14 \mathrm{~d}$ of age (see Fig. 3). The greatest effects on neonatal growth were noted with $14 \mathrm{~d}$ of postnatal L-NAME treatment (Fig. 3, $C-F$ ), as opposed to only prenatal L-NAME administration (Fig. 3, $A$ and $B)(p<0.05)$. In addition, growth rates were not influenced by postnatal mode of delivery (i.e. per os versus intraperitoneally; Fig. $3, C, E$, and $F$, versus $D$ ) or combined prenatal plus postnatal (Fig. 3, $E$ and $F$ ) versus postnatal L-NAME only (Fig. 3, $C$ and $D$ ) treatment.

A clinical hallmark of hypertrophic pyloric stenosis is vomiting. Although rats do not vomit it was readily noticeable that the abdomens of L-NAME-treated pups were grossly enlarged. Subsequently, indices of hypertrophic pyloric stenosis were evaluated in a different group of animals. Because pups receiving prenatal plus postnatal L-NAME were most significantly affected, this protocol was adopted, and L-NAME administration was extended to 21 postnatal days. In addition, as growth retardation and gastric distension were not influenced by mode of delivery (i.e. per os versus intraperitoneally), due to ease of administration postnatal L-NAME was administered through maternal breast milk (per os).

On the 14th or 21st postnatal day after an overdose of ketamine:xylazine, an intracardiac puncture was done to collect 1-2 $\mathrm{mL}$ of blood for analyses (see below). A midline incision was made, and the abdominal and pulmonary cavities were exposed. Stomachs were inflated through an esophageal catheter with normal saline $\left(20 \mathrm{~cm} \mathrm{H}_{2} \mathrm{O}\right.$ pressure). The volume 
from the esophageal-abdominal inlet to the pyloric outlet was measured. Protein content of the stomach was measured with a Bio-Rad protein assay kit (Richmond CA), using a Bio-Rad model 3550 enzyme-immunoassay reader. Protein standard was prepared with lyophilized bovine $\gamma$-globulin. Sections of stomach were weighed and then placed in a desiccator for 72 $\mathrm{h}$ to obtain dry weights. In a subset of animals the pyloric sphincter was removed and prepared for standard histologic evaluation (hematoxylin and eosin). The small intestine from the duodenum to the ileo-cecal valve was removed, cleansed of fecal material, measured, weighed, and then placed in a desiccator to obtain dry weights. In addition, fetal kidneys, brain, and liver were also removed and weighed.

Blood pressure elevation is a hallmark of cNOS inhibition and was examined on postnatal d 21 (attempted on postnatal d 14 , but was not technically feasible in a reliable manner). A subgroup of newborns were anesthetized with intramuscular ketamine:xylazine anesthesia $(40 \mathrm{mg} / \mathrm{kg}: 4 \mathrm{mg} / \mathrm{kg})$ to maintain anesthesia, as determined by corneal reflexes. The internal carotid artery was exteriorized, cannulated (PE10), and connected to a Gould pressure transducer (model P3800, GouldStatham, Oxnard, CA) for continuous measurements of mean arterial blood pressure. Calibrations of pressure transducers were done with a mercury manometer. After a postsurgical stabilization period resulting in a stable baseline mean arterial blood pressure measurement, the blood pressure was monitored for a 15-min period. The newborns were killed by exsanguination via the carotid cannulation. Hearts were removed and weighed after 14 and $21 \mathrm{~d}$ of life.

To explore infectious and inflammatory components for the delayed postnatal growth, blood was evaluated for hematocrit and white blood cell number. Circulating leukocyte levels were manually quantified. Cardiac blood was collected and mixed with 9 volumes of $3 \%$ acetic acid (1:10 dilution). The Neubauer chamber was charged with a drop of the blood mixture, and white cells were counted with light microscopy. In addition, myeloperoxidase activity was determined in the ileum as previously described (5).

Statistical analysis. To compare biochemical values and weights for different treatments, one- way analysis of variance was done followed by Duncan's multiple range test (20). For all statistical data, a $p<0.05$ value was considered to represent a significant difference between the compared values.

\section{RESULTS}

\section{Prenatal Studies}

Chronic second and late third trimester NOS inhibition with $L$-NAME. The presence of L-NAME did not influence drinking or feeding behavior as both were consumed at comparable quantities, regardless of dose or duration of administration (Table 1). Maternal weight gain was also comparable, regardless of dose or duration of administration.

Fetal growth was retarded in a dose- (0.3 versus $1.0 \mathrm{mg} / \mathrm{mL})$ and time-dependent fashion by L-NAME administration; evident with $4 \mathrm{~d}$ (gestational d 16-19) or $14 \mathrm{~d}$ (gestational d 6-19) of prenatal treatment when compared with control fetuses (Fig. $2 ; p<0.05$ ). Consistent with the reductions in pup
Table 1. Maternal intake and weight gain

\begin{tabular}{cccc}
\hline Intake & Food $(\mathrm{g} / \mathrm{k} / \mathrm{d})$ & Water $(\mathrm{mL} / \mathrm{k} / \mathrm{d})$ & Weight gain $(\mathrm{g} / \mathrm{d})$ \\
\hline L-NAME & & & \\
$0.3 \mathrm{mg} / \mathrm{mL}(4 \mathrm{~d})$ & $117 \pm 6$ & $184 \pm 23$ & $15.3 \pm 0.5$ \\
$1.0 \mathrm{mg} / \mathrm{mL}(4 \mathrm{~d})$ & $115 \pm 7$ & $192 \pm 32$ & $15.1 \pm 0.8$ \\
$0.3 \mathrm{mg} / \mathrm{mL}(14 \mathrm{~d})$ & $110 \pm 15$ & $181 \pm 25$ & $14.8 \pm 1.2$ \\
$1.0 \mathrm{mg} / \mathrm{mL}(14 \mathrm{~d})$ & $109 \pm 11$ & $179 \pm 30$ & $13.9 \pm 0.6$ \\
Control & $115 \pm 8$ & $196 \pm 12$ & $14.85 \pm 1.01$ \\
\hline
\end{tabular}

Values are mean \pm SEM. L-NAME $0.3 \mathrm{mg} / \mathrm{mL}(4 \mathrm{~d})=6$ dams, L-NAME $1.0 \mathrm{mg} / \mathrm{mL}(4 \mathrm{~d})=6 \mathrm{dams}, \mathrm{L}-\mathrm{NAME} 0.3 \mathrm{mg} / \mathrm{mL}(14 \mathrm{~d})=4 \mathrm{dams}$, L-NAME $1.0 \mathrm{mg} / \mathrm{mL}(14 \mathrm{~d})=4 \mathrm{dams}$, and control $=8 \mathrm{dams}$.
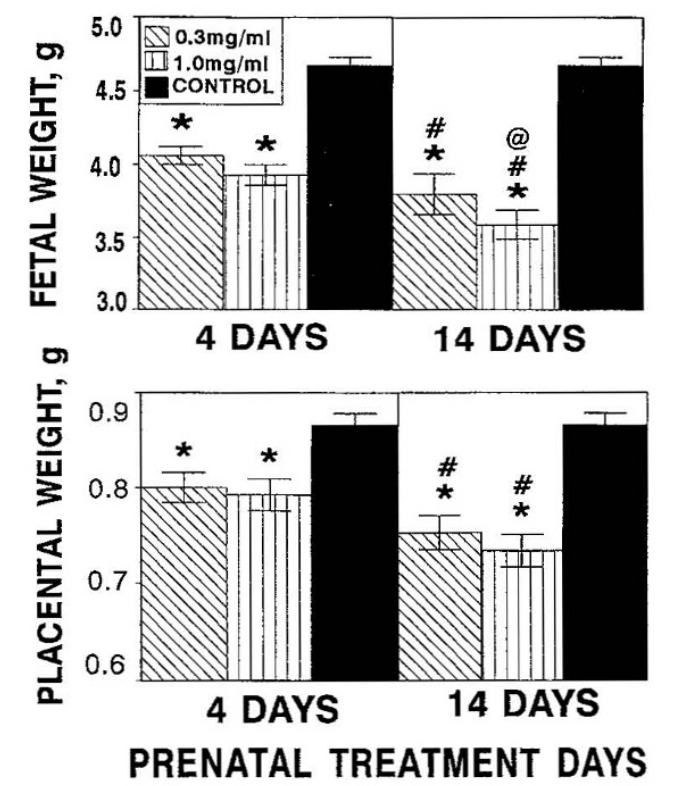

Figure 2. Pup and placental weights from untreated dams (control, water only) or dams treated prenatally with L-NAME for 4 (gestational d 16-19) or 14 (gestational days and 6-19) days, at 0.3 or $1.0 \mathrm{mg} / \mathrm{mL}$ in the drinking water. The columns represent the mean \pm SEM for $n=4-8$ litters/group/dose; L-NAME $0.3 \mathrm{mg} / \mathrm{mL}$ (4 d) = 67 pups; L-NAME $1.0 \mathrm{mg} / \mathrm{mL}(4 \mathrm{~d})=66$; L-NAME $0.3 \mathrm{mg} / \mathrm{mL}(14 \mathrm{~d})=51 \mathrm{pups}$; L-NAME $1.0 \mathrm{mg} / \mathrm{mL}(14 \mathrm{~d})=55$ and control $=92$ pups). The $*$ depicts a significant difference in the L-NAME groups compared with water controls $(p<0.05)$. The@ depicts a significant difference $(p<0.05)$ between L-NAME $0.3 \mathrm{mg} / \mathrm{mL} v s$ L-NAME $1.0 \mathrm{mg} / \mathrm{mL}$ treatment groups for each prenatal treatment day. The \# depicts a significant difference $(p<0.05)$ between treatment days for each L-NAME dose.

size was a time-dependent reduction in placental weight (Fig. $2 ; p<0.05)$ when compared with controls. There were no differences in the number of pups/litter or stillbirths in any treatment group.

Aminoguanidine studies. Fetal and placental growth was not altered after 7 prenatal days (gestational d 13-19) of aminoguanidine $(6.34 \pm 0.07 \mathrm{~g}$ and $0.81 \pm 0.01 \mathrm{~g}$, respectively) when compared with controls $(6.12 \pm 0.05 \mathrm{~g}$ and 0.85 $\pm 0.01 \mathrm{~g})$.

\section{Perinatal Studies}

Postnatal growth. In rats exposed to L-NAME only prenatally, postnatal growth remained significantly retarded on the 14th d of life, despite discontinuation of L-NAME at birth (Fig. 3, $A$ and $B, p<0.05$ ) when compared with control groups (Fig. $3, G$ and $H$ ). Postnatal treatment with L-NAME resulted in 


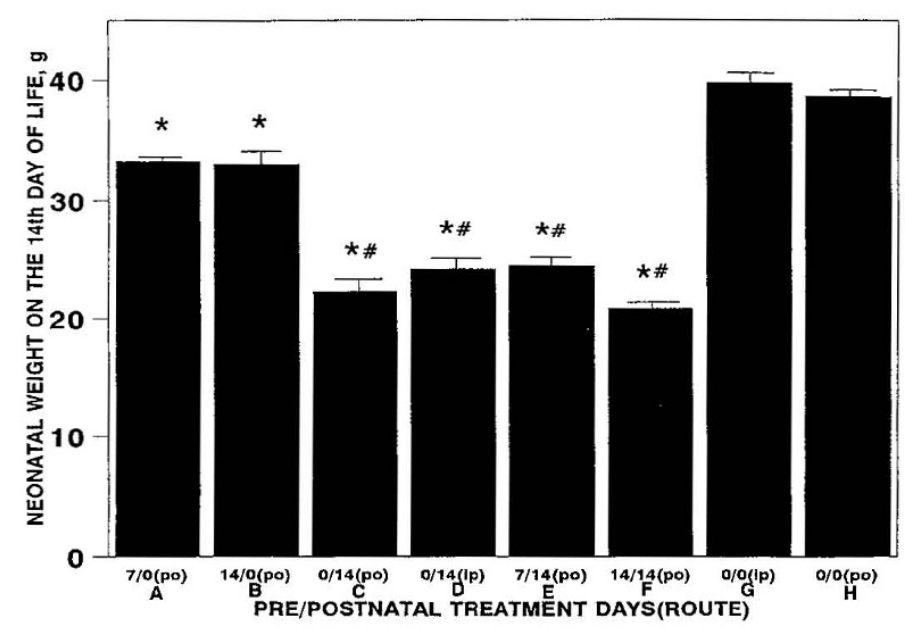

Figure 3. Neonatal weights in grams on the 14th day of life after the specified prenatal and postnatal days of either oral ( $p o$, maternal breast milk) (1.0 $\mathrm{mg} / \mathrm{mL}, \sim 180 \mathrm{mg} / \mathrm{kg} / \mathrm{d}$ ) or intraperitoneal (ip, $180 \mathrm{mg} / \mathrm{kg} / \mathrm{d}$ ) L-NAME. $A=7$ prenatal days of oral L-NAME and zero postnatal treatments. $B=14$ prenatal days of oral L-NAME and zero postnatal treatments. $C=$ zero prenatal days of L-NAME and 14 postnatal days of oral L-NAME. $D=$ zero prenatal days of L-NAME and 14 postnatal days of intraperitoneal L-NAME. $E=7$ prenatal days of oral L-NAME and 14 postnatal days of oral L-NAME. $F=14$ prenatal days of oral L-NAME and 14 postnatal days of oral L-NAME. $G=$ zero prenatal days of L-NAME and intraperitoneal injections of water for 14 postnatal days. $H=$ zero prenatal and postnatal days of L-NAME. The columns represent the mean \pm SEM. The * depicts a significant difference in the L-NAME groups compared with water ( $p o$ or $i p)$ controls $(p<0.05 ; n=6-8$ litters/group). The \# depicts a significant difference in the L-NAME postnatal treatment groups compared with the L-NAME prenatal only treatment groups ( $p<0.05 ; n=6$ litters/group; $10-12$ pups/litter).

growth retardation at $14 \mathrm{~d}$ of life, whether administering it orally via maternal breast milk (Fig. $3 C$ ) or by intraperitoneal injection (Fig. 3D) and regardless of whether prenatal L-NAME was administered (Fig. 3, $E$ and $F$ ) or not (Fig. 3, $C$ and $D$ ) when compared with control groups (Fig. 3, $G$ and $H$ ). LNAME-treated pups also had a delay in the time it took to open their eyes, an index of their maturational retardation. On d 14 only $19 \%$ of L-NAME-treated pups had their eyes open, compared with $82 \%$ of control pups. When growth was followed for 6 mo of life there was no evidence of "catch-up" growth (Fig. 4).

Postnatal growth retardation. Although the L-NAMEtreated newborns were significantly smaller than their water control counterparts, their stomachs were noticeably enlarged and engorged with food. We established a series of tests to determine whether these observations were due to HPS. There was a significant increase in stomach weight/pup weight, stomach volume/pup weight, concomitant with a decrease in small intestine weight/length (thickness) in the pups receiving 7 prenatal and 14 or 21 postnatal days of L-NAME compared with control pups (Fig. 5). In addition, gastric wall protein content was increased in 14- and 21-d-old L-NAME treated pups $(3141 \pm 258$ and $4421 \pm 221 \mu \mathrm{g} / \mathrm{g}$, respectively) compared with their control counterparts $(2001 \pm 235$ and $3100 \pm$ $210 \mu \mathrm{g} / \mathrm{g}$, respectively) $(p<0.05)$. Stomach edema was not present as assessed by comparative wet-to-dry weights in L-NAME-treated 14- and 21-d-old pups (5.13 \pm 0.32 and 5.04 \pm 0.19 , respectively) compared with control counterparts $(4.83$

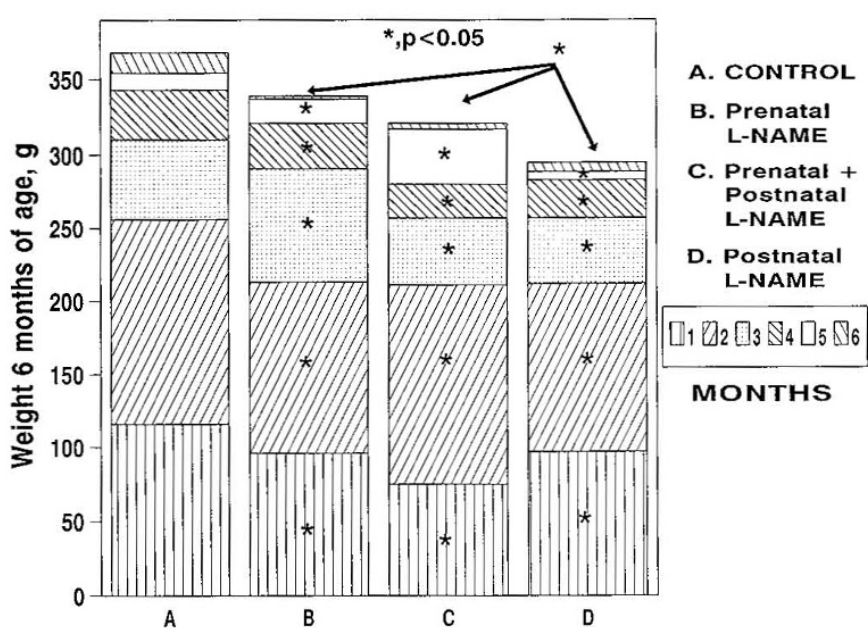

Figure 4. Pup weight (grams) after the specified prenatal and postnatal treatments with oral ( $p o$, maternal breast milk) $(1.0 \mathrm{mg} / \mathrm{mL}, \sim 180 \mathrm{mg} / \mathrm{kg} / \mathrm{d})$ L-NAME at 1-6 mo of age. $A=$ Control, zero prenatal or postnatal treatments with L-NAME. $B=7$ prenatal days of oral L-NAME and no postnatal treatments. $C=7$ prenatal days of L-NAME and 14 postnatal days of oral L-NAME. $D=$ zero prenatal days of L-NAME and 14 postnatal days of oral L-NAME. The columns represent the mean weight in grams for 1-6 mo of age. The * depicts a significant difference in the L-NAME groups compared with water control at each month ( $p<0.05 ; n=4$ litters/group; 10-12 pups/litter).
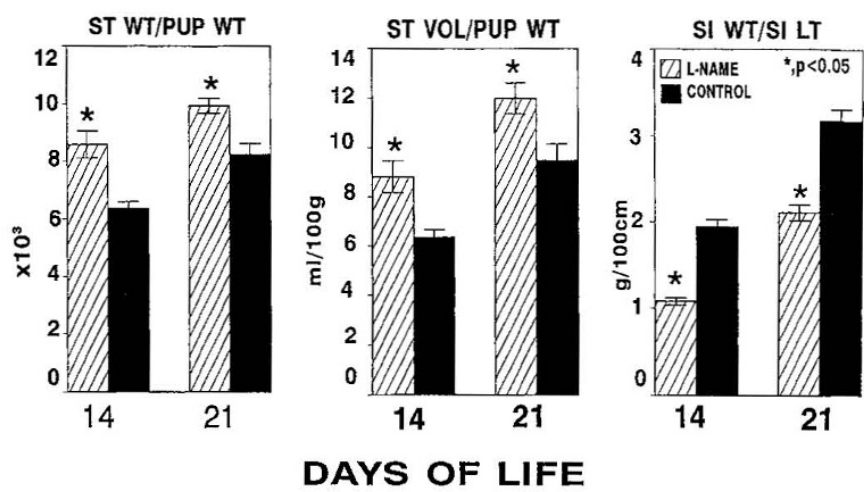

Figure 5. Indices of hypertrophic pyloric stenosis. Stomach weight/pup weight $(S T$ WT/PUP WT $)\left(\times 10^{3}\right)$, stomach volume/pup weight $(S T$ VOL/PUP $W T)(\mathrm{mL} / 100 \mathrm{~g}$ of pup weight $)$, small intestine weight/small intestine length (SI $W T / S I L T)(\mathrm{g} / 100 \mathrm{~cm}$ of small intestine) in pups receiving 7 prenatal and 14 or 21 postnatal days of L-NAME, compared with control 14- and 21-d-old pups. The columns represent the mean \pm SEM. The * depicts a significant difference in the L-NAME groups compared with water controls $(p<0.05 ; n=4$ litters/group; 10-12 pups/litter).

\pm 0.18 and $4.99 \pm 0.19$, respectively). Together these findings are consistent with hypertrophy of the gastric musculature secondary to an obstruction of its outlet with a secondary atrophy of the small intestine, i.e. hypertrophic pyloric stenosis. Histologic evaluation of the pyloric sphincter revealed muscularis hypertrophy and hyperplasia of the circular muscle of the muscularis propria of the pylorus after 14 or $21 \mathrm{~d}$ of postnatal L-NAME when compared with pyloric sphincters of 14- or 21-wk-old control pups (Fig. 6).

Growth retardation was asymmetric, consistent with a nutritional deficit. Brain weight/body weights in L-NAME treated 14- and 21-d-old pups were significantly increased when compared with control counterparts (Table 2) and are consistent 


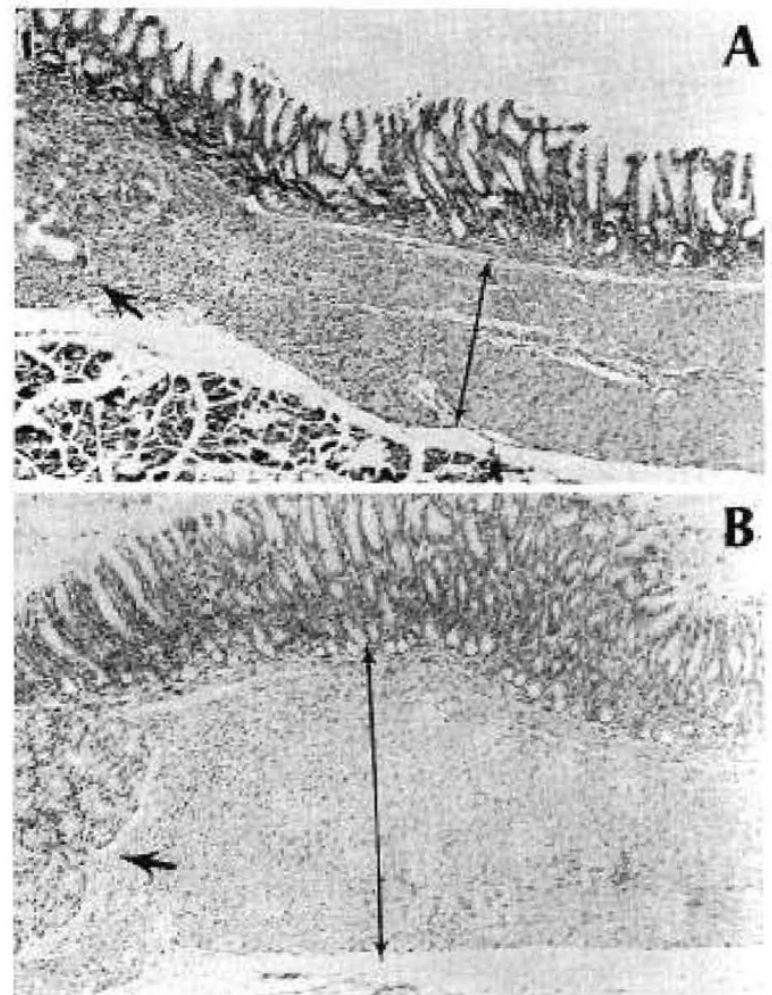

Figure 6. Hematoxylin and eosin-stained sections of the pyloric sphincter reveals hypertrophy of the circular smooth muscle at the region of pyloric valve after 3 wk of postnatal L-NAME $(B)$ when compared with the pyloric sphincters of age matched control pups $(A)$. The size of circular muscle is highlighted in both panels by the double-headed arrow. The single arrow notes the glands of Brunner and the beginning of the duodenum, to assist orientation. Original magnification $\times 100$ for both panels.

with asymmetric growth secondary to malnutrition anticipated in hypertrophic pyloric stenosis.

Systemic mean arterial blood pressure at $21 \mathrm{~d}$ was increased in the L-NAME-treated newborns compared with untreated controls (Table 2). Heart weight/pup weights were not significantly different between groups. Hematocrits were not significantly different. Kidney and liver weights/body weight were similar in all groups (Table 2).

All markers of an infectious or inflammatory process including white blood counts and intestinal myeloperoxidase were similar in all study groups (Table 2).

\section{DISCUSSION}

NO formation is up-regulated in pregnancy (10). Both constitutive and inducible pathways appear to contribute to NO production in the utero-placental unit. Studies of the role of NO in the fetus and newborn have been limited; primarily focusing on its role in the pulmonary circulation. We have recently shown that administration of the predominately cNOS inhibitor, L-NAME, throughout the last third of pregnancy results in reduction of fetal and placental growth (13). To better address the pathophysiologic mechanism responsible for these findings, we undertook a series of experimental studies designed to determine to what degree the gestational timing of NOS inhibitor administration would alter fetal growth, whether inadequate NO production through inhibition of the iNOS isoforms would alter fetal growth and whether NOS inhibition during the neonatal period would also effect neonatal growth and maturation.

L-NAME predominately inhibits activity of the cNOS isoforms, whereas aminoguanidine predominately inhibits the activity of the iNOS isoforms. After prenatal L-NAME, fetal and placental growth was reduced in a dose- and timedependent fashion (Fig. 2). Aminoguanidine did not alter intrauterine growth, and the purpose of a sustained expression of iNOS in pregnancy remains to be determined. In addition, maternal health was not compromised (data not shown). These findings suggest that growth retardation induced by L-NAME was most likely due to inhibition of cNOS. As placental growth was also compromised, inhibition of endothelial-derived NO may compromise placental function, limiting the maternal-fetal exchange of oxygen, nutrients, and metabolic wastes. This proposal agrees with work demonstrating that both NOS inhibition (21) and inhibition of NO-activated guanylate cyclase (22) augments umbilical-placental vascular tone, whereas umbilical blood flow decreases. Studies demonstrating that intracellular generation of NO by both glyceryltrinitrate and $S$ nitro- $N$-acetylpenicillamine vasodilates the fetal-placental circulation preconstricted with the thromboxane mimetic U46619 (22). Collectively our study and those cited suggest that constitutive release of NO, throughout pregnancy, regulates resting umbilical-placental vascular resistance and placental growth, and impacts greatly on fetal well being.

Postnatal treatment with L-NAME resulted in postnatal growth retardation that was significantly more dramatic than prenatal administration (Fig. 3, $C-F$, versus $A$ and $B$, respectively). This growth retardation was asymmetric, with brain sparing (Table 1), suggesting a nutritional origin. L-NAME was effective in the neonate whether it was administered orally to the mother and therefore reached the newborn via maternal breast milk (Fig. 3, $C, E$, and $F$ ) or by direct intraperitoneal injection to the newborn (Fig. $3 D$ ) and regardless of whether prenatal L-NAME was administered (Fig. 3, $A$ and $B$ ) or not (Fig. 3, $C$ and $D$ ). L-NAME was directly administered to the neonates by the intraperitoneal route to discount the possible influence of maternal factors and to assure optimal delivery of L-NAME to the neonates. The present results are the first to suggest that L-NAME is secreted in an active form in breast milk.

The 14-d-old L-NAME-treated pups, although visibly smaller than their control counterparts, had stomachs that appeared disproportionally enlarged and engorged with food, whereas their intestines appeared thin and friable. HPS is a common disorder of the gastrointestinal tract in human infants. It is characterized by gastric-outlet obstruction associated with hypertrophy, hyperplasia, or both, of the circular musculature of the pylorus secondary to failure to relax. Although it has been recognized as a disease entity for more than two centuries (23), its physiopathologic mechanism is not known. Recently a genetic knockout strains of mice devoid of the neuronal isoform of cNOS has been described. Surprisingly, these animals displayed little pathology, except marked HPS (24).

Neuronal NOS is distributed throughout the myenteric plexus in the rat gut from stomach to distal colon (25), acting 
Table 2. Neonatal organ weight, health, and maturational status

\begin{tabular}{|c|c|c|c|c|}
\hline \multirow[b]{2}{*}{ Variable } & \multicolumn{2}{|c|}{ Day 14} & \multicolumn{2}{|c|}{ Day 21} \\
\hline & Control & L-NAME & Control & L-NAME \\
\hline Brain wt. (g) & $1.08 \pm 0.03$ & $1.13 \pm 0.02$ & $1.25 \pm 0.03$ & $1.34 \pm 0.04$ \\
\hline Brain/pup wt. $\left(\times 10^{2}\right)$ & $2.74 \pm 0.18$ & $5.24 \pm 0.17^{*}$ & $2.29 \pm 0.08$ & $4.40 \pm 0.13^{*}$ \\
\hline Heart/pup wt. $\left(\times 10^{2}\right)$ & $4.99 \pm 0.12$ & $5.23 \pm 0.23$ & $4.90 \pm 0.01$ & $4.97 \pm 0.14$ \\
\hline Liver/pup wt. $\left(\times 10^{2}\right)$ & $3.28 \pm 0.47$ & $3.00 \pm 0.22$ & $3.87 \pm 0.24$ & $3.52 \pm 0.35$ \\
\hline Kidney/pup wt. $\left(\times 10^{2}\right)$ & $1.38 \pm 0.21$ & $1.09 \pm 0.01$ & $1.11 \pm 0.02$ & $1.18 \pm 0.02$ \\
\hline Hematocrit $(\%)$ & $26.8 \pm 1.2$ & $26.0 \pm 2.1$ & $30.8 \pm 1.2$ & $32.3 \pm 1.3$ \\
\hline Mean arterial blood pressure $(\mathrm{mm} \mathrm{Hg})$ & NA & NA & $60 \pm 5$ & $93 \pm 6^{*}$ \\
\hline Leukocyte count $\left(\right.$ cells $\left./ \mathrm{mm}^{3}\right)$ & $8.30 \pm 2.6$ & $8.53 \pm 3.6$ & $7.09 \pm 1.01$ & $7.88 \pm 0.77$ \\
\hline Intestinal MPO (units/100 mg) & $113.4 \pm 9.6$ & $121.1 \pm 5.5$ & $77.3 \pm 9.8$ & $71.6 \pm 15.7$ \\
\hline Eyes open $(\%)$ & 82 & $19^{*}$ & 100 & 100 \\
\hline
\end{tabular}

Values are mean \pm SEM for $6-8$ litters/group; NA, not available; ${ }^{*} p<0.05$ control $v s$ L-NAME. MPO $=$ myeloperoxidase.

as an important mediator of relaxation of the esophagus (26), stomach (27), intestine (28), colon (29), and pylorus (30). The excitatory innervation of the pylorus is largely cholinergic from the vagal nerve (31). Inhibitory innervation, producing relaxation of the pyloric smooth muscle, is thought to be secondary to non-adrenergic non-cholinergic neurotransmitters such as vasoactive intestinal polypeptide (32). However, incomplete blockade of non-adrenergic non-cholinergic neurotransmitter-mediated relaxation by VIP antiserum suggests that a non-VIP component is also involved in producing relaxation of the pylorus (33). NO has recently been shown to act synergistically with VIP to cause vasorelaxation, whereas LNAME decreases inhibitory junction potentials in the pyloric canal (30). It has also recently been shown that pyloric tissues from infants with HPS have enteric nerve fibers enlarged and distorted and do not contain NOS activity (34) that is normally present in nerve fibers of the pyloric musculature. Our studies and those cited suggest that lack of NOS in enteric nerves of the smooth musculature of the pylorus sphincter may account for the defect in relaxation of the pyloric sphincter in infantile HPS and that NO may be the non-VIP component responsible for relaxation of the pylorus.

In our study, exposure to the cNOS (neuronal) inhibitor, L-NAME, in the neonatal period links neuronal NOS to HPS and affirms the role of NO in newborn gastric function. The stomach was hypertrophied, whereas the small intestine was atrophied, suggesting an obstruction of nutrient delivery from the stomach to the intestine. Malnutrition was so severe as to cause marked growth retardation with classic sparing of the brain over viscera. Although it remains to be demonstrated, this study raises the possibility that NO donors may be an effective medical treatment of pyloric stenosis and other forms of pylorospasm. Although a nonsurgical approach for this condition would be welcome, potential systemic complications (hypotension, inhibition of platelet aggregation) would need to be judiciously evaluated and limited.

In conclusion the fetal complications appear to result from compromised placental growth, consistent with inhibition of endothelial NOS activity. The neonatal complications predominately result from malnutrition secondary to hypertrophic pyloric stenosis and hypertension, consistent with inhibition of neuronal and endothelial NOS activity, respectively. Synthesis of NO from L-arginine by a constitutive NOS isoform is essential for fetal and neonatal growth and development.

\section{REFERENCES}

1. Palmer RMJ, Ferrige AG, Moncada S 1987 Nitric oxide release accounts for the biological activity of endothelium-derived relaxing factor. Nature 327:524-526

2. Bredt DS, Hwang PM, Synder SH 1990 Localization of nitric oxide synthase indicating a neural role for nitric oxide. Nature 347:768-770

3. Radomski MW, Palmer RMJ, Moncada S 1990 Characterization of the L-argininc: nitric oxide pathway in human platelets. Br J Pharmacol 101:325-328

4. McCartney-Francis N, Allen JB, Mizel DE, Albina JE, Xie Q-W, Nathan CF, Wahl SM 1993 Suppression of arthritis by an inhibitor of NOS. J Exp Med 178:749-754

5. Miller MJS, Sadowska-Krowicka H, Chotinaruemol S, Kakkis JL, Clark DA 1993 Amelioration of chronic ileitis by NOS inhibition. J Pharmacol Exp Ther 264:11-16

6. Yui Y, Hahori R, Kosuga K, Eizawa H, Hiki K, Ohkawa S, Ohnishi K, Terao S, Kawai C 1991 Calmodulin-independent nitric oxide synthase from rat polymorphonuclear neutrophils. J Biol Chem 266:3369-3371

7. Rees DD, Palmer RMJ, Schulz R, Hodson HF, Moncada S 1990 Characterization of three inhibitors of endothelial NOS in vitro and in vivo. Br J Pharmacol 101:746-752

8. Rees DD, Palmer RMJ, Hodson HF, Moncada S 1989 A specific inhibitor of nitric oxide formation from L-arginine attenuates endothelium-dependent relaxation. $\mathrm{Br} \mathrm{J}$ Pharmacol 96:418-424

9. Misko TP, Moore WM, Kasten TP, Nickols GA, Corbett JA, Tilton RG, McDaniel ML, Williamson JR, Currie MG 1993 Selective inhibition of the inducible nitric oxide synthase by aminoguanidine. Eur J Pharmacol 233:119-125

10. Conrad KP, Joffe GM, Kruszyna H, Kruszyna R, Rochelle LG, Smith RP, Chavez JE, Mosher MD 1993 Identification of increased nitric oxide biosynthesis during pregnancy in rats. FASEB J 7:566-571

11. Natuzzi ES, Ursell PC, Harrison M, Buscher C, Riemer RK 1993 Nitric oxide synthase activity in the pregnant uterus decreases at parturition. Biochem Biophys Res Commun 194:1-8

12. Myatt L, Brockman DE, Langdon G, Pollock JS 1993 Constitutive calcium-dependent isoform of nitric oxide synthase in the human placental villous vascular tree. Placenta 14:373-383

13. Diket AL, Pierce MR, Munshi UK, Voelker CA, Eloby-Childress S, Greenberg SS, Zhang XJ, Clark DA, Miller MJS 1994. Nitric oxide inhibition causes intrauterine growth retardation and hind limb disruptions in rats. Am J Obstet Gynecol 171:12431250

14. Grisham MB, Specian RD, Zimmerman TE 1994 Effects of nitric oxide synthase inhibition on the pathophysiology observed in a model of chronic granulomatous colitis. J Pharmacol Exp Ther 271:1114-1121

15. Gardiner SM, Compton AM, Bennett T, Palmer RMJ, Moncada S 1990 Regional hemodynamic changes during oral ingestion of $N^{G}$-nitro-L-arginine methyl ester in conscious Brattelboro rats. Br J Pharmacol 101:10-12

16. Baylis C, Mitruka B, Deng A 1992 Chronic blockade of nitric oxide synthesis in the rat produces hypertension and glomerular damage. J Clin Invest 90:278-281

17. Miller MJS, Clark DA 1994 Nitric oxide synthase inhibition can initiate or prevent gut inflammation: role of enzyme source. Agents Actions 41:C231-C232

18. Cross AH, Misko TP, Lin RF, Hickey WF, Trotter JL, Tilton RG 1993 Aminoguanidine, an inhibitor of inducible nitric oxide synthase, ameliorates experimental autoimmune encepalomyelitis in SJL mice. J Clin Invest 93:2684-2690

19. Corbett JA, Tilton RG, Chang K, Hasan KS, Ido Y, Wang JL, Sweetland MA, Lancaster JR, Williamson JR, McDaniel ML 1992 Aminoguanidine, a novel inhibitor of nitric oxide formation, prevents diabetic vascular dysfunction. Diabetes 41:552556

20. Steel RGD, Torrie JH 1960 Principles and Procedures of Statistics. McGraw-Hill, New York, pp 51-73

21. Chang J-K, Roman C, Heymann MA 1992 Effect of endothelium-derived relaxing factor inhibition on the umbilical-placental circulation in fetal lambs in utero. Am J Obstet Gynecol 166:727-734

22. Myatt L, Brewer AS, Langdon G, Brockman D 1992 Attenuation of the vasoconstrictor effects of thromboxane and endothelin by nitric oxide in the human fetalplacental circulation. Am J Obstet Gynecol 166:224-230

23. Hayes MA, Goldenberg IS 1957 The problems of infantile pyloric stenosis. Int Abst Surg 104:105-138

24. Huang PL, Dawson TM, Bredt DS, Snyder SH, Fishman MC 1993 Targeted disruption of the neuronal nitric oxide synthase. Cell 75:1273-1286 
25. Belai A, Schmidt HW, Hoyle CHV, Hassall CJS, Saffrey MJ, Moss J, Forstermann U, Murad F, Burnstock G 1990 Colocalization of nitric oxide synthase and NADPHdiaphorase in the myenteric plexus of the rat gut. Neurosci Lett 143:60-64

26. Tottrup A, Svane D, Forman A 1991 Nitric oxide mediating NANC inhibition in opossum lower esophageal sphincter. Am J Physiol 260:G385-G389

27. Desai KM, Sessa WC, Vane JR 1991 Involvement of nitric oxide in the reflex relaxation of the stomach to accommodate food or fluid. Nature 351:477-479

28. Shuttleworth CWR, Murphy R, Furness JB 1991 Evidence that nitric oxide participates in non-adrenergic inhibitory transmission to intestinal muscle in the guinea-pig. Neurosci Lett 130:77-80

29. Dalziel HH, Thornbury KD, Ward SM, Sanders KM 1991 Involvement of nitric oxide synthetic pathway in inhibitory junction potentials in canine proximal colon. Am J Physiol 260:G789-G792
30. Bayguinov O, Sanders KM 1993 Role of nitric oxide as an inhibitory neurotransmitter in the canine pyloric sphincter. Am J Physiol Soc 264:G975-G983

31. Mir SS, Telford GL, Mason GR, Ormsbee HS 1979 Noncholinergic, nonadrenergic inhibitory innervation of the canine pylorus. Gastroenterology 76:1443-1448

32. Kamata K, Sakamoto A, Kasuya Y 1988 Similarities between the relaxations induced by vasoactive intestinal peptide and by stimulation of the NANC neurons in the rat stomach. Naunyn-Schmiedeberg's Arch Pharmacol 338:401-404

33. D'Amato M, De Beurme FA, Lefebvre RA 1988 Comparison of the effect of vasoactive intestinal polypeptide and non-adrenergic non-cholinergic neurons stimulation in the cat gastric fundus. Eur J Pharmacol 152:71-76

34. Vanderwinden JM, Mailleux P, Schiffmann SN, Vanderhaeghen JJ, De Laet MH 1992 NOS activity in infantile hypertrophic pyloric stenosis. N Engl J Med 327:511-515 